\title{
Gênero, adolescências e prevenção ao HIV/aids
}

\author{
Araci Asinelli-Luz ${ }^{*}$ e Nelson Fernandes Júnior ${ }^{* *}$
}

Resumo: O advento da aids e sua íntima relação com os estudos da sexualidade humana apontam para a importância das questôes de gênero para o sucesso da prevenção diante da epidemia. O enfoque fortemente centrado no uso do preservativo masculino evidencia que, além do conhecimento sobre o corpo e a sexualidade, relaçóes de poder entre homens e mulheres precisam ser redimensionadas para que as estratégias que privilegiam o sexo seguro possam ser incorporadas no cotidiano das relaçóes sexuais. Este artigo, fruto de pesquisa realizada entre adolescentes de ambos os sexos, com idades de 17 e 19 anos, na cidade de Curitiba, ajuda-nos a entender como elas/eles pensam a sua sexualidade e a prevenção da infecção pelo HIV, indicando em que situaçóes vivenciam comportamentos de prevenção e quando negligenciam diante da sua condição peculiar de vulnerabilidade.

Palavras-chave: adolescência; gênero; prevenção do HIV; sexualidade; aids.

\section{Gender, adolescences and HIV/aids prevention}

Abstract: The advent of AIDS and its close relation with the studies of human sexuality point to the importance of gender issues for successful prevention to face this epidemic. The approach that is strongly focused on the use of male condoms shows that besides the knowledge of the body and sexuality, power relations between men and women need to be revised so that strategies that emphasize safer sex can be incorporated to everyday sexual relations. This article results from a research conducted among adolescents from both genders, aged 17 and 19, in the city of Curitiba, Brazil. It is intended to help us understand how they think about sexuality and prevention against HIV infection, indicating situations in which they engage in preventive behaviors and when they are neglectful in face of their peculiar situation of vulnerability.

Key words: adolescence; gender; HIV prevention; sexuality; AIDS.

Depois da revolução sexual dos anos 1960 e 1970, sem dúvida, o advento da aids entre as doenças sexualmente transmissíveis - DSTs _ - vem mobilizando novas posturas e diálogos entre as diferentes áreas do conhecimento. Um

\footnotetext{
* Professora do Programa de Pós-Graduação em Educação da Universidade Federal do Paraná (UFPR). Brasil. araciasinellihotmailcom

* Mestre em Educação pelo Programa de Pós Graduação, Setor de Educação da Universidade Federal do Paraná (UFPR). Brasil. Psicólogo Clínico.nelfes@terra.com.br
} 
dos campos mais afetados é o das políticas públicas para a adolescência e a juventude, no que tange à educação, à saúde sexual e reprodutiva, pois, conforme pesquisas publicadas nos últimos anos, a aids assume dimensões de uma pandemia. Em 1998, conforme veiculado pela UnAids (1999), falava-se que na América Latina e no Caribe, aproximadamente 65 mil indivíduos entre 15 e 24 anos de idade adquiriram o HIV (Vírus da Imunodeficiência Humana).

Dados divulgados pela Unesco (2002) estimavam que aproximadamente um terço da população mundial se encontrava entre os 10 e os 24 anos de idade. Segundo a Organização Mundial da Saúde, é nessa faixa etária que se concentra metade das infecçóes pelo HIV em todo o mundo. Esses dados evidenciam a situação crítica que se apresenta, priorizando que a população jovem seja colocada no topo da pauta de debate público sobre as políticas de saúde e educação, em resposta à epidemia de HIV, no Brasil e no mundo.

De acordo com o relatório denominado Situação da População Mundial, do Fundo de População das Nações Unidas (UNFPA, 2003), temos mais de 1,2 bilhão de adolescentes com idade entre 10 e 19 anos. Destes, $87 \%$ vivem em países em desenvolvimento. O relatório aponta os principais problemas enfrentados por esses/as jovens, como pobreza, dificuldade de acesso à educação e doenças. E, entre as doenças, a aids: a cada 14 segundos, um/a jovem é infectado/ a, isto é, todos os dias, seis mil jovens são contaminados pelo vírus da aids, o HIV. A aids atinge mais as garotas que os rapazes - são 7,3 milhôes de jovens mulheres vivendo com o HIV e 4,5 milhões de rapazes. Por características biológicas, o risco de infecção numa relação sexual sem proteção é de duas a quatro vezes mais alto entre as mulheres. Na América Latina e no Caribe estima-se que 560 mil jovens vivam com o HIV.

Segundo o site http://www.adolesite.aids.gov.br, criado pelo Ministério da Saúde para ajudar as/os adolescentes com informaçôes sobre questôes sexuais, o último Boletim Epidemiológico - Aids - (Brasil, 2007) ali divulgado, publicação trimestral do Ministério da Saúde, registrou, desde o início da década de 1980 até dezembro de 2007, 474.267 casos de aids no Brasil. Deste total, 10.337 casos de aids estão entre as/os adolescentes na faixa etária dos 13 aos 19 anos.

Dados do Ministério da Saúde, até dezembro de 2007, revelam que, na população entre 13 e 24 anos, o número de casos acumulados de DST/aids é de 54.964 , dos quais 31.355 adolescentes e jovens do sexo masculino e 23.609 do sexo feminino (Brasil, 2007), indicando nitidamente uma questão de gênero ${ }^{1} \mathrm{e}$

1. Gênero como construção histórico-social sobre as características biológicas da sexualidade, trazida para a prática social relativa ao masculino e ao feminino. 
os fatores de vulnerabilidade ${ }^{2}$ e prevenção ${ }^{3}$. Além de as/os adolescentes iniciarem a vida sexual mais cedo, aliam a isso a desinformação, a prática do sexo desprotegido ${ }^{4}$ e a escolha imatura do/a parceiro/a.

Compreender o comportamento do/a adolescente no contexto de sua sexualidade - paradigmas comportamentais, afetivos, cognitivos - e trabalhar com essa população em tempos de aids sob a perspectiva de gênero diante da prevenção foi o que motivou a pesquisa que dá suporte a este artigo, como uma das contribuiçóes da educação para o enfrentamento da epidemia da aids entre adolescentes e com novos subsídios às diretrizes de educação sexual, de forma a promover no/a adolescente senso de auto-eficácia, tomada de decisão, responsabilidade e compromisso de saúde para com a sua própria sexualidade.

Sobre esse objeto de estudo temos as seguintes premissas:

1. as características individuais concernentes a questôes de gênero, a iniciação sexual precoce, a competência verbal, a habilidade em planejar o futuro, a variáveis familiares, a pressóes grupais, a auto-estima e outras, podem predispor a/o adolescente a comportamentos sexuais que a/o coloquem em maior vulnerabilidade;

2. as representações de prevenção manifestas pela/o adolescente e que determinam sua conduta preventiva variam em função do gênero (feminino ou masculino): no feminino, estão mais atreladas às questôes do envolvimento emocional (não planejamento); e, no masculino, às realizações sexuais (prazer) e desempenho em si.

3. as manifestaçôes do egocentrismo descrito por Piaget $(1969$; 1976) e retomado por Elkind (1975), o qual estaria relacionado à não-adoção de medidas preventivas em relação às práticas sexuais, pela falta de tomada de consciência sobre o risco são observadas na adolescência;

4. a adoção de conduta preventiva no experienciar da sexualidade dos/as jovens adolescentes não se efetiva mediante educação sexual que se concentre apenas na transmissão de informaçốes científicas, sem que se promova compreensão emocional da sexualidade e senso de autoconsciência real;

5. a consciência da necessidade de prevenção vai se tornando mais efetiva com o desenvolvimento cognitivo do/a adolescente.

2. A vulnerabilidade é aqui entendida como o conjunto de fatores de natureza biológica, epidemiológica, social e cultural cuja interação amplia ou reduz o risco ou a proteção de uma pessoa ou da população em relação a uma determinada doença, a certa condição ou a um dano.

3. Todas as estratégias dirigidas ao conjunto da população, num esforço para evitar a ocorrência de fatos indesejáveis, para reduzir a incidência ou o índice de ocorrência de novos casos.

4. Relação sexual sem o uso de preservativo (masculino ou feminino). 
Nesse sentido, é mister para os/as educadores/as apreender as percepçóes que o/a adolescente tem da realidade em que vive. Para mudar o comportamento é importante reconhecer o objeto, atribuindo-lhe assim um valor. Tal valor é que facilitará a adoção de novas atitudes e de práticas de prevenção.

Em um país de dimensões continentais e clivagens tão desiguais como o Brasil, a resposta à epidemia do HIV/aids na adolescência passa, necessariamente, pelo enfoque intersetorial - saúde e educação -, abrangendo as esferas da estrutura governamental e a sociedade civil organizada.

\section{Gênero na sexualidade adolescente e HIV/aids}

As discussões sobre os novos padrões de comportamento estão trazendo para a esfera da sexualidade e da saúde reprodutiva a figura masculina. Mota (1998) relata que o uso da camisinha aparece relacionado ao poder de controle do homem sobre a reprodução e a fertilidade feminina, desde que o contexto indomável e incontrolável da sua sedução sexual não o leve a relações sexuais sem a devida proteção.

Num tempo de epidemias sexualmente transmissíveis, julgamos que reconhecer mais profundamente os domínios do corpo e do erótico na vida sexual diária de rapazes e moças nos levará a uma melhor compreensão do transgredir normas de prevenção do universo adolescente.

Na década de 1980, o vírus da imunodeficiência humana (HIV) veio integrar a lista das DSTs, agravando os problemas já existentes, na medida em que a forma mais comum de transmissão, na maioria dos países, é a relação sexual com penetração e ejaculação em coito não protegido (Glasel, 1991).

Quando comparados/as às/aos jovens (Moreira, 2002), os/as adolescentes apresentam maiores riscos de contrair uma DST por razôes associadas à tendência de ter maior número de parceiras/os, sucessivas/os ou simultâneas/os; de envolver-se em relaçôes sexuais não protegidas; e de ser menos/as seletivos/ as na escolha de parceiras/os. Com o processo de ampliação da fase da adolescência (iniciação sexual precoce e casamento tardio), o tempo de exposição aos riscos de contrair uma DST é maior.

Como elementos adicionais contributivos para que a taxa de infecção por DST seja mais elevada entre adolescentes do que na população jovem e adulta, Moreira (2002) enumera a ausência de serviços de prevenção; o custo e a aquisição da camisinha; o desconhecimento de como usá-la; o preconceito e a falta de confiança em seu uso; a dificuldade de portá-la; e o desconforto que causa.

Não adianta que os adultos reconheçam a importância da prevenção na vida dos jovens e os fatores que os vulnerabilizam. É 
preciso que os próprios jovens reconheçam o significado e a importância da prevenção em suas vidas, sendo este reconhecimento a mola propulsora para o protagonismo juvenil da epidemia do HIV/Aids (Unesco, UnAIDs, 2002, p. 16).

Ainda na atualidade vemos uma grande incidência de adolescentes e jovens infectando-se pelo HIV, seja pela baixa prevalência do uso de preservativos, seja pelo uso de diversos tipos de drogas injetáveis ou simplesmente pelo desconhecimento de questôes relativas ao comportamento sexual. Esses índices são preocupantes, devido à precocidade e às consequiências que esse padrão de comportamento pode causar no indivíduo.

Considerando-se que o/a portador/a do HIV pode viver em média durante dez anos sem apresentar os sintomas da doença, provavelmente, o número de pessoas que se tornaram HIV-positivas, na faixa etária de 15 a 24 anos, deve ter-se elevado. Em outra perspectiva, o risco de o adolescente masculino contrair o HIV tem amplas repercussões sobre sua disseminação, em razão do maior número de parceiras que usualmente tem em suas práticas sexuais, o que o transforma em agente não identificável de transmissão. Portanto, desenvolver ações de prevenção voltadas para essa população adolescente é uma prioridade para o controle da epidemia no País.

O Ministério da Saúde percebeu o aumento dos casos de aids na população da faixa etária de 13 a 19 anos. Em 2000 verificou-se que a ocorrência de aids é mais elevada em garotas que em rapazes, ocorrendo o perigo de aumento da transmissão vertical do vírus (da mãe para o/a filho/a, durante a gestação, parto ou amamentação), aliando essa questão à grande incidência de gravidez na adolescência.

De 2000 a 2002 o Ministério da Saúde foi notificado da ocorrência de 531 novos casos de aids em meninas de 13 a 19 anos, contra 372 casos em rapazes da mesma faixa etária. Verificou-se uma inversão na relação de 2:1, no início da atividade sexual. Na faixa etária entre 20 e 24 anos, a relação praticamente se igualou, com a notificação de 2.299 casos em mulheres e 2.346 casos em homens, nesse mesmo período (Brasil, 2003).

A feminização cada vez mais evidente da aids parece envolver, além de uma maior vulnerabilidade biológica da mulher ao HIV, uma desigualdade observável na distribuição de poder entre os gêneros, que diz respeito aos diferentes espaços de negociação em relação às questôes que envolvem os direitos sexual e reprodutivo, prazer e auto-conhecimento sobre o corpo. Observamos ainda valores e sentimentos diferenciados em relação à parceria quanto às noções de fidelidade. Além disso, a mulher também tem sido considerada menos exposta ao risco, talvez pela sua entrada mais tardia na dinâmica da epidemia, não se 
enquadrando nos, inicialmente denominados, grupos de risco (Brasil/Boletim Epidemiológico - Aids, 2002).

No entanto, pesquisa de Paschoalick $(2007$, p.13) reafirma que o comportamento tradicional masculino pode contribuir para "aumentar a vulnerabilidade dos homens frente à infecção pelo HIV", com base nos estudos de Guerreiro, Ayres e Hearst (2002), que apontam vários comportamentos relacionados à masculinidade, tais como "sentir-se forte, ser incapaz de recusar uma mulher, considerar que o homem tem mais necessidade de sexo que a mulher, sendo esse desejo incontrolável, não usar o preservativo por medo de perder a ereção".

No Brasil, da mesma forma, os primeiros casos de aids notificados eram relativos a homossexuais masculinos e usuários de drogas injetáveis. No entanto, esse perfil vem sofrendo mudanças no curso da epidemia.

Os índices apresentados neste breve resumo histórico demonstram a vital importância da promoção de pesquisas de prevenção e de intervenção para conhecer, caracterizar e compreender a realidade concreta da população adolescente brasileira, suas representações acerca da doença, suas formas mais comuns de infecção e suas atitudes diante da prevenção.

\section{A pesquisa com adolescentes e a prevenção da infecção do HIV e aids}

Analisar a fala de adolescentes sobre suas representaçóes e sobre seus comportamentos relativos à prevenção da infecção pelo HIV e da aids ilustra a necessária intervenção em educação em saúde numa abordagem de gênero. Para isso, foram entrevistados dez adolescentes masculinos e dez femininos, com idades de 17 a 19 anos, efetivamente matriculados no ensino médio em escola da rede pública estadual e em universidade pública, selecionados pelas variáveis sexo/idade/série, escolhidos aleatoriamente, por sorteio na lista de classe.

Os critérios de escolha estiveram condicionados aos seguintes pares: $3^{\text {a }}$ série do ensino médio, adolescentes de 17 anos, cinco garotos e cinco garotas; e $1^{\circ}$ ano do terceiro grau, adolescentes de 19 anos $^{5}$, cinco rapazes e cinco moças.

A idade mínima de dezessete anos foi escolhida por compor uma faixa etária em que as/os adolescentes provavelmente já se apresentam férteis (menarca e semenarca) e ativos/as sexualmente; o limite de dezenove anos, aparentemente por haver uma possibilidade de maior compreensão do tema, e também pela

5. A Organização Mundial de Saúde considera adolescente a faixa etária de 12 a 19 anos completos. Para o Estatuto da Criança e do Adolescente, a adolescência compreende a faixa etária de 12 a 18 anos, podendo, nos casos expressos em lei, aplicar-se o Estatuto, excepcionalmente, às pessoas entre dezoito e vinte e um anos de idade. 
possibilidade de encontrarmos adolescentes sexualmente ativos/as, conforme nos indicam os resultados das estatísticas sobre o início da atividade sexual, e sujeitos a maiores riscos de gravidez não planejada e de infecção por HIV e outras DSTs.

Para a coleta de dados utilizamos entrevista individual de cerca de trinta minutos cada, realizada in loco nas instituiçōes de ensino, precedida por rapport, gravada na sua totalidade. A técnica de entrevista tem relevância ímpar quando o foco é a representação/percepção, pois privilegia a palavra dos sujeitos da pesquisa. Permite que o/a entrevistado/a se expresse de acordo com seu próprio vocabulário. Permite também a realização de comparações devido ao relativo grau de homogeneidade assegurado (idade, sexo e escolaridade) e propicia análises gerais e sistemáticas das informações.

Sobre a entrevista, Gil (1999, p. 117) afirma que:

Pode-se definir como a técnica em que o investigador se apresenta frente ao investigado $\mathrm{e}$ lhe formula perguntas, com o objetivo de obtenção dos dados que interessam à investigação. A entrevista é, portanto, uma forma de interação social. Mais especificamente, é uma forma de diálogo assimétrico, em que uma das partes busca coletar dados e a outra se apresenta como fonte de informação.

Em razão de a natureza da entrevista estar voltada para a sexualidade dos sujeitos - representaçõos de prevenção em relação à infecção pelo HIV-, orientamos as perguntas de forma tal que a/o entrevistada/o explicitasse algumas ações de conduta ou que permitisse facilitar o aparecimento de alguns elementos que talvez não surgissem numa entrevista comum. Antes disso os/as estudantes tiveram esclarecimento sobre a pesquisa, sobre seus objetivos e sobre a utilização dos dados e assinaram o Termo de Consentimento Esclarecido e Assinado.

As informaçôes recebidas foram codificadas de acordo com o grupo ao qual pertencem os/as entrevistados/as, conforme o que segue: 17M (adolescentes masculinos com 17 anos); 17F (adolescentes femininas com 17 anos); 17MF (adolescentes masculinos e adolescentes femininas com 17 anos); 19M (adolescentes masculinos com 19 anos); 19F (adolescentes femininas com 19 anos); 19MF (adolescentes masculinos e adolescentes femininas com 19 anos); $M$ (adolescentes masculinos com 17 e 19 anos); F (adolescentes femininas com 17 e 19 anos). 


\section{A voz e a vez da adolescência: oportunidade de reflexão}

Quanto ao ser sexualescente ${ }^{6}$, o Grupo $M$ conceitua a sexualidade com expressiva dificuldade, à primeira vista, relacionando o termo, primeiramente, a prazer, a atração, a mudanças do corpo, a sacanagens e a mulher. No Grupo $19 \mathrm{M}$ podemos encontrar algumas referências à palavra sentimento. Todos dizem já ter experienciado uma relação sexual, acontecida entre os 15 e/ou 16 anos. O Grupo F conceitua sexualidade de maneira mais ampla e com maior despojamento, relacionando ao termo não só os substantivos apresentados pelo Grupo M, mas também as idéias de responsabilidade, conflitos de valores, sentimento, carinho; local, momento e companheiro certos; amor, cuidado com a saúde, gravidez e doenças.

No Grupo 17F, todas as adolescentes são virgens e, no Grupo 19F, duas delas já tiveram experiências de relação sexual. Dessa forma, a idade média da primeira relação sexual do Grupo F é de 19 anos e a menarca ocorreu aproximadamente aos 13 anos.

No Grupo M, a maior parte das relações sexuais de iniciação deram-se sem programação, foram inesperadas e em locais nada propícios. No Grupo 17M, dois adolescentes não utilizaram qualquer método de prevenção. Não havia também envolvimento afetivo. $\mathrm{O}$ restante (três) utilizou o preservativo masculino. No Grupo 19M, todos fizeram uso de algum método preventivo, mas apenas um deles não utilizou a camisinha masculina na iniciação sexual pelo fato de a garota estar tomando anticoncepcional.

No Grupo F, as duas adolescentes não virgens programaram a primeira relação sexual e fizeram uso de camisinha masculina, em comum acordo com os namorados. As adolescentes virgens revelaram experiências de intimidade com seus parceiros e posicionamentos quanto ao uso de ou de anticoncepcional quando optarem pela relação sexual. $O$ manter-se virgem está cercado de inúmeros motivos: esperar o momento certo, com a pessoa certa, no local certo, para ter boa lembrança do momento; mãe austera, preconceito de ainda ser virgem, insegurança no método contraceptivo, falta de sentimentos e confiança no parceiro.

Quanto à manutenção da prática de prevenção, somente um adolescente, em cada Grupo M, diz utilizar camisinha em todas as relaçôes sexuais. Aqueles do Grupo 17M, que não experienciaram outras relaçõos após a iniciação sexual, mencionam a intenção de utilizar preservativo nas próximas; um deles não usa, pois a camisinha, segundo ele, diminui o prazer, e o outro dispensa o uso

6. Fernandes Júnior adotou esse termo em sua dissertação de mestrado (2005) para representar o/ a adolescente que inicia sua vida sexual ativa. 
pelo fato de a namorada utilizar anticoncepcional. No Grupo $19 \mathrm{M}$ as características repetem-se: a camisinha deixa de ser usada quando o adolescente conhece melhor a garota, e esta usa pílula. Em função das condições do momento e do local, menciona um adolescente deste Grupo, negligencia o uso.

De forma geral, todos os adolescentes manifestaram consciência da necessidade de utilização de medidas de prevenção ao HIV/aids em todas as relações sexuais, motivados pelo risco de contrair a doença ou de engravidar; por não conhecer a saúde do parceiro (a); por desconhecer o comportamento do outro e por cuidar da própria saúde; por risco de terminar a relação afetiva.

Sempre...camisinha...salvo três vezes que eu não usei.

Acho que não existe esse não usar, é só usar.

Ésaber da história dela, acho que saber um pouco dela, se conhecer como ela é, por exemplo... se ela exige a camisinha no começo ou até bom tempo, depois eu confiaria mais nela em não usar, do que simplesmente ela, no começo, já deixar de fazer sem... ela não exigir. Nesse relacionamento, a gente fez o teste da aids juntos e isso deixou a gente mais tranquiilo.

Em contrapartida, o desprazer causado pelo uso da camisinha é mencionado por um adolescente do Grupo 19M:

Na verdade, o problema não é a camisinha, o problema é a gente [...] só que a gente às vezes não usa por falta de responsabilidade, porque às vezes está bom, émelhor sem camisinha.

Uma adolescente do Grupo 19F alerta quanto ao fato de que as garotas se previnem mais contra a gravidez precoce do que em relação à aids:

Depois de um tempo eu comecei a tomar remédio, porque depois de um certo tempo que você pega confiança na pessoa, sei lá, dai não tinha mais o porquê [...] ele fez exame, minha mäe fez ele fazero teste de HIV [...] ele achava ruim, que disse que não é a mesma coisa [...] pramim tanto faz né, eu comecei a tomar um comprimido que até fez malpra mim [...] faço exames periodicamente no ginecologista [... esquecijá umas quatro vezes... eu tomei a pílula do dia seguinte... em todas essas vezes... de medo.

A necessidade da utilização de métodos de prevenção é identificada de maneira unânime pelos atores dos Grupos $\mathrm{M}$ e F, quando se associa a relação sexual com a ausência de vínculo afetivo (sexo e afetos). No Grupo F, quatro adolescentes não fazem associação entre prevenção e afetos, opinando sempre pela prevenção, independentemente de vínculos afetivos; o mesmo acontece com dois adolescentes do Grupo M. A falta de confiança, a tentativa de evitar 
danos aos adolescentes, o desconhecimento das atitudes e dos comportamentos do parceiro ou parceira, o risco de gravidez, a infidelidade e a inconsistência do sentimento são os motivos elencados para essa decisão.

Eu fiz errado, não conhecia ela direito, não sabia se ela tinha um outro cara, nada, e transei com ela sem camisinha. [...] Bom, eu amo muito a minha namorada, adoro ela, confio pra caramba nela, e ela..., a gente só usa realmente camisinha [...] quando ela acha que tá perto de descer a menstruação dela, é uma coisa assim. Relação sexual não importa o sentimento envolvido, tem que ter prevençäo.

Mas vocêpode amarsem conhecer muito bem a pessoa,... mas quando ama, mesmo assim eu acho que tem que ter algum método contraceptivo.

Quanto à homossexualidade, o Grupo $M$ evidencia a necessidade da utilização de camisinhas entre homens que fazem sexo com homens, devido ao risco de contaminação no sexo anal. O Grupo 19M considera que as práticas preventivas são as mesmas necessárias nos relacionamentos heterossexuais e não manifestam conteúdos homofóbicos. O mesmo ocorre no Grupo 19F, que, no entanto, aponta drogas e tatuagens como fatores de riscos associados a esses indivíduos.

Inclusive eu queria argumentar sobre o masculino... que o anal tem mais chance de pegar uma aids do que uma penetração pênisvagina [...] te falar que eu não sei direito como é(entre mulheres)... sabe... mas... (risos).

Acho que a questão não é homossexual ou hétero, ela é... digamos... universal, geral.

[...] com mulheres não, entre lésbicas não.

O Grupo $17 \mathrm{M}$ demonstra sinais evidentes de homofobia e de violência verbal. Parte do Grupo 17F também considera que as práticas preventivas sejam as mesmas necessárias nos relacionamentos heterossexuais (preservativos e exame laboratorial), e duas adolescentes não têm certeza quanto à necessidade de prevenção. No Grupo F, palavras como "nojento" e "horrível" são pontuadas.

Nossa! Nem gosto de pensar nisso, que, nossa, acho uma coisa tão nojenta. Eu acho ridiculo, mas, deve ter proteção também, né? Senão...

Porque eu acho que também passa doença, né? Apesar de ser horrivel, né? [...]

Eu acho que o mesmo numero de riscos ocorre com qualquer um, né? 
Homem não é se é., homem com homem, mulher com mulher, eu acho que...

Quero que foda-se.

O assunto mulheres que fazem sexo com mulheres deixa evidente o desconhecimento, em todos os grupos de adolescentes entrevistados/as, das formas de contaminação pelas DSTs. Acreditam que práticas de prevenção também sejam necessárias, mas, notadamente no Grupo F, os questionamentos e os gracejos imperam. No Grupo 17F, três garotas acreditam que, por não haver penetração, não há risco de contaminação.

Olha, não sei se na mulher que faz sexo com mulherprecisa, mas eu imagino que sim, só fica complicado pensar como, mas no homem com certeza, na mulher não sei se precisa... nunca pensei nisso. (risos).

A não ser que conheça bem a pessoa, saiba, tenha feito um teste, [...] ai não, aísei lá... se não acha nojento, vai e faz.

A grande maioria dos entrevistados aponta um maior risco de contaminação no contato sexual com pessoas que fazem uso de drogas lícitas e ilícitas, em virtude da prática de troca de seringas e dos efeitos alucinógenos produzidos pela droga, que interferem no bom senso do usuário quanto às medidas preventivas. No Grupo $17 \mathrm{~F}$, duas adolescentes não sabem fazer correlação com os assuntos.

Com referência a rótulos e a estereótipos, os grupos masculinos manifestam-se favoráveis ao uso de medidas de prevenção à gravidez precoce e às DSTs em todas as relações sexuais, independentemente da aparência (bonito/feio; gordo/magro; jovem/maduro) ou da condição financeira (rico/pobre) da companheira, mas acabam revelando, no decorrer dos questionamentos, que algumas características da garota, como bonita, rica, magra, madura/jovem, podem amenizar a obrigatoriedade da utilização de preservativos.

Não. Todos são riscos, não tem distinção. Às vezes, se a mulher for meio nojentona assim... é até meio preconceito, mas existe... eu utilizaria [...] com a bonita geralmente você tende assim a não usarné... mas na hora você não teria tanto medo.

Achar que não vai precisar com a mais rica... isso é preconceito, eu acho, mas as pessoas sempre pensam assim.

Já tive essa experiencia em que a mais simples se cuidava melhorque a da classe social melhor.

O Grupo $\mathrm{F}$ posiciona-se a favor das medidas de prevenção, independentemente dos rótulos enumerados, e em todas as relaçôes sexuais. A troca frequien- 
te de parceiros ou de parceiras conduz os atores entrevistados a um maior alerta para a prevenção da gravidez e da contaminação por DSTs, levando algumas adolescentes do Grupo 17F a manifestarem-se a favor de utilizar conjuntamente as camisinhas masculina e feminina, ou de associar o anticoncepcional ao preservativo.

Não, acho que raça, cor e situação financeira, acho que não vai interferirnisso dai, não. Porque pra mim as pessoas são iguais, não interessa se tem casas boas, emprego bom, se uma pessoa não tem a cabeça no lugar, não é o dinheiro que vai garantir.

A mesma coisa porque o..., com os dois, feio, rico, pobre, é..., ah, tanto faz, eu vou fazer a mesma coisa é com qualquer um, eu vou fazer as mesmas coisas, épode acontecer as mesmas coisas, entendeu, então eu vou me prevenir da mesma maneira, entendeu?

Utilizaria mais com o que rodou mais assim, né?... Porque daí, corre mais risco do que o menos, né? Se prevenir mais, né? Eu usando e ele usando. Camisinha feminina. A camisinha masculina. É, ou, ou eu usar anticoncepcional [...].

Prevenção e responsabilidade pretendem sintetizar os conceitos de prevenção em relação às DSTs. De uma forma geral, os Grupos $\mathrm{M}$ e $\mathrm{F}$ apontam as camisinhas (masculina e feminina) para o conceito de prevenção em relação às DSTs, além de controle médico. O Grupo 17M manifesta alguns enganos quanto às formas de infecção pelo HIV e aos sintomas da doença; o Grupo 17F opta também pelos cuidados com a transfusão de sangue e por maior diálogo com o parceiro, como medidas preventivas.

Quanto às fontes informativas em que os adolescentes recebem noçôes de sexualidade e de prevenção, de maneira geral, a escola acaba sendo a principal delas, mas não a única mencionada por todos os grupos entrevistados. A família, em maior ou menor grau; amigos; pesquisas em livros, na Internet, em revistas, em jornais; disque aids; médicos e especialistas também são ou poderão vir a ser fontes de consulta, em necessidades presentes ou futuras. Alguns adolescentes sentem-se satisfeitos com o que sabem; outros gostariam de aprofundar o conhecimento a respeito da sexualidade, de forma geral.

Estar contaminado com uma DST mobiliza diversos sentimentos nos atores dos Grupos M e F. Medo, susto, aflição, vergonha são relatados pelo Grupo M. Os de 17 anos manifestam dúvidas quanto às suas ações pós-contaminação, mas buscariam tratamento medicamentoso; consideram-se vulneráveis, caso não utilizem medidas preventivas ou caso o preservativo estoure. Relatos de invulnerabilidade e de disseminação proposital do vírus são encontrados no Grupo 19M: 
Fui ao médico e me tratei, no aspecto moral não pesou nada, mas tomei todos os cuidados médicos.

Me assusta um pouco, aids me assusta mais [...] Num relacionamento sem camisinha, ai não tem anticoncepcional, não tem nada... aíe só a camisinha [...] mas depois que eu me estruturasse eu provavelmente procuraria algum tratamento, procuraria um médico, tentaria levar uma vida nomal.

Com aids eu acho que eu ia ficarmuito depressivo, eu era capaz de espalhar.. pelo menos no começo quando eu ficasse sabendo, quando soubesse.

Nunca me senti correndo esse risco, apesar de correr sempre.

Desorientação, desespero, isolamento social, culpa, abstinência sexual, infelicidade, vontade de morrer e chorar são sentimentos e ações mobilizadas no Grupo F. Ambos os grupos optam por tratamento medicamentoso. O Grupo $17 \mathrm{~F}$ nunca imaginou a possibilidade de contaminação (são virgens), mas sentem-se vulneráveis quanto à transfusão de sangue ou a acidentes com objetos perfurocortantes. Duas adolescentes consideram-se invulneráveis, com as medidas de prevenção que estabelecem:

Mas com relação ao vímis da aids é complicado, não sei...eu iria atrás de ... tomaria remédio, procurar tratamento dentro do possivel. Não sei, mas é muito complicado, acho que eu procuraria tratamento, mas acho que me isolaria do mundo.

Primeiro tem que falar com a pessoa que me transmitiu, pois ela pode nem saber que tem. Iria procurar cuidar de mim, me tratar.

Em ambos os Grupos, M e F, a contaminação pelo HIV é tida como de maior agravo, devido à ausência de cura da aids na atualidade. Dessa forma, os sentimentos mais pesarosos estão voltados para essa doença:

Iria tentar esconder o máximo possivel, não que eu tivesse preconceito contra mim mesma, assim, mas sei que as outras pessoas assim teriam preconceito..., tentaria viver minha vida nomal, tentaria esconder isso da maioria das pessoas, assim, fazer tratamento.

\section{Das representações}

A sexualidade é a dimensão do ser humano que envolve gênero, identidade, orientação, fantasia, desejo, erotismo, envolvimento emocional, crenças, atitudes, valores, atividades, práticas, papéis, relacionamentos, contracepção e, notadamente, saúde sexual e reprodutiva. 
Marcas de gênero são fortemente observadas no conceito de sexualidade entre rapazes, em que a sexualidade se entrelaça mais com o prazer, e entre moças, que têm a sexualidade entrelaçada com a afetividade; nas características das situações vividas na iniciação sexual: planejadas, entre elas, ou inesperadas, entre eles; e na idade em que essa iniciação ocorre.

A idade média encontrada para a primeira relação sexual é cerca de três anos menor para os rapazes (entre 15 e 16 anos) do que para as moças (19 anos), com maior probabilidade, para eles, de vivenciá-la no início da adolescência, época de parcos conhecimentos e informações referentes às práticas preventivas ao envolver-se sexualmente (Bemfam, DHS, 1996; Brasil, 2003).

A idade média da primeira relação sexual para adolescentes do sexo feminino, aqui registrada (19 anos), afasta-se da média encontrada (15,5 anos) em dados mais recentes da literatura consultada (MS, 2003). Os dados aqui apresentados podem denotar uma possível tendência destas garotas a aguardar uma ocasião de maior segurança emocional e a escolha de um parceiro mais adequado; podem também se justificar pelo fato de parte das jovens estar frequientando o último ano do ensino médio conforme relata Camarano (2003).

O preservativo masculino como método de prevenção tem representaçôes que igualmente provocam atenção sobre tal prática ou não-prática. Uma delas situa-se no tabu de que o prazer masculino é muito diminuído quando dela se faz uso.

Fidelidade e sentimentos de amor são razões que podem também levar a que muitos adolescentes abram guarda no uso da camisinha e assim negligenciem a prevenção. A confiança que muitas adolescentes depositam nos parceiros quanto à fidelidade sexual é preocupante.

A vulnerabilidade a que estão sujeitas as adolescentes no campo da sexualidade pode ser registrada na pesquisa em distintas unidades temáticas, como o desconhecimento das formas de contaminação entre mulheres que fazem sexo com mulheres, revelando quão pouco conhecem o próprio corpo.

A ausência de figuras parentais ou de adultos de referência para propiciar orientação e educação sexual é claramente percebida, o que contribui para a manutenção de representaçôes que denotam conflitos éticos e de valores morais, notadamente entre as adolescentes virgens do sexo feminino.

O grau de conhecimento das medidas de prevenção à aids revelado pelos/as adolescentes entrevistados/as seria suficiente para evitar a infecção pelo HIV, mas, algumas atitudes e alguns comportamentos denotam inconsistência entre discurso e prática de prevenção, possibilitando o envolvimento em relaçóes sexuais sem proteção.

Destacamos representações discriminatórias diante de posturas homofóbicas, reveladas por expressôes de preconceitos, de nojo e de violência verbal, deno- 
tando falta de conhecimento nas esferas do saber sexual. A esse respeito, Castro, Abramovay e Silva (2004) já haviam alertado que diversos preconceitos e discriminações são manifestados em nome de uma sexualidade considerada "normal", consentida pelos padrôes culturais. A partir da concepção de sexualidade de Michel Foucault (1988), Dinis (2007, p. 138) permite-nos verificar o quanto a sexualescência reflete "saberes e poderes que buscam normatizar, controlar e estabelecer verdades acerca do sujeito na relação com seu corpo e seus prazeres".

Representações que apareceram nas falas das/os adolescentes entrevistados - prevenir primeiramente a gravidez precoce, depois o HIV; não planejar a primeira relação sexual, porque o próprio corpo vai saber identificar a hora certa; adotar para pouco sexo só camisinha e para sexo frequiente, também anticoncepcional; acreditar que contatos isentos da penetração não oferecem riscos de contaminação; utilizar conjuntamente as camisinhas masculina e feminina como método de prevenção associado; acreditar na fidelidade do namorado e deixar de utilizar a camisinha como método de prevenção à aids; crer que sexo anal ofereça maior chance de se contaminar, mas que sexo entre mulheres não ofereça perigo; pensar que não é preciso usar camisinha toda hora..., é preciso, mas não dá pra lidar; transar com camisinha é o método mais completo, porém não é o mais prático, é melhor sem; usar camisinha dada pelo postinho não é garantia, nelas não dá pra confiar — , denotam o quanto ainda se tem por fazer.

No estudo deste complexo mosaico fica claro que se trata, não de uma única adolescência, porém de uma pluralidade desta, identificando-se formas de ser, de estar e de pensar, conforme gêneros, ciclos etários, indivíduos e acontecimentos que podem predispor o/a adolescente a comportamentos sexuais que os envolvam em riscos pessoais. Recomendamos, portanto:

1. investir em pesquisas nas quais maior número de representaçóes possa ser desvendado, para melhor refletir sobre temas importantes referentes à sexualidade de adolescentes e a seu experienciar sexual;

2. realizar avaliaçôes de políticas e de programas que contemplem temas de saúde sexual, reprodutiva e de adolescência, de forma quantitativa e qualitativa, com especial atenção à prevenção da infecção do HIV/aids e aos respectivos impactos sobre suas vidas;

3. motivar o surgimento de projetos que intencionem construir uma masculinidade avessa a estereótipos, a divisóes sexuais de poderes e a assimetrias nas relaçóes de gênero;

4. subsidiar movimentos sociais e ONGs que tenham o objetivo de orientar adolescentes na luta por direitos sexuais e reprodutivos cada vez mais equânimes entre os gêneros; 
5. capacitar adequadamente os professores quanto à temática da sexualidade humana sob a ótica da prevenção, uma vez que as escolas representam um espaço onde, por um lado, as/os adolescentes se reúnem, estabelecem e compartilham códigos de comportamentos, iniciam namoros e desenvolvem relacionamentos amorosos; por outro lado, é onde recebem informação, tratamento esclarecido sem preconceitos e expressam dúvidas com menor constrangimento. É via privilegiada para os esforços de prevenção contra DST e gravidez precoce;

6. investir nos programas voltados à prevenção e à disponibilização de informaçôes entre pares, estimulando dessa forma o protagonismo juvenil;

7. incentivar a criação de linha de pesquisa e/ou de programa de pós-graduação na área da educação sexual.

\section{Referências bibliográficas}

ABRAMOVAY, M., CASTRO, M. G.; SILVA, L. B. Juventude e sexualidade. Brasília: UNESCO Brasil, 2004.

BEMFAM; DHS, 1996; FNUAP - Brasil. Publicação: CNPD - Jovens acontecendo na trilha das políticas públicas, vol. 1, p.131. In: Dossiê adolescentes: início precoce das relaçóes sexuais e baixo uso de métodos contraceptivos. Disponível em: $<$ http://www.redesaude.orb.br/dossies/ html/body_ad-inicioprecoce.html s. Acesso em: 27 jul. 2004.

BRASIL. Ministério da Saúde. Coordenação Nacional de DST e Aids. Boletim Epidemiológico - Aids. Brasília, 2007 Disponivel em: <http://www.adolesite.Aids.gov.br/adolesite.htm> Acesso em: 04/01/2008.

BRASIL. Ministério da Saúde. Coordenação Nacional de DST e Aids. Boletim Epidemiológico - Aids. 27a. a 40a. Semana Epidemiológica. De jun.2001 a set. 2001. Brasília : MS, 2001.

BRASIL. Ministério da Saúde. Secretaria de Políticas de Saúde. Coordenação Nacional de DST e Aids. Boletim Epidemiológico - Aids. a. XV, n. 2. 48a 2001 à 13a. 2002 semanas epidemiológicas. De out.2001 a mar.2002.

BRASIL. Ministério da Saúde. Coordenação Nacional de DST e Aids. Boletim Epidemiológico - Aids. a. XVI n. 01. 14 a a 52ª Semanas epidemiológicas, abr. a dez. de 2002. Brasília, 2002. disponível em: <http://www.abcdAids.com.br/> Acesso em: 25 mai.2003.

BRASIL. Ministério da Saúde. Notícias. No combate à Aids. Assessoria de Imprensa da Coordenação de DST/AIDS. Disponível em: <www.saude.gov.br/notícias>. Acesso em: 28. nov. 2005.

BRASIL. Ministério da Saúde. O programa brasileiro, 2002. Brasília : Ministério da Saúde, 2002.

BRASIL. Ministério da Saúde. Pesquisa sobre comportamento sexual e percepçốes da população brasileira sobre HIV/AIDS. Brasília: Coordenação Nacional de DST e AIDS; 2000. 
CAMARANO, A. A. et al. Jovens brasileiros: sexualidade, gravideze Aids. Fev. 2003, no prelo. DINIS, N.F. Educação, relaçôes de gênero e exclusão. In: GUÉRIOS, E, STOLTZ, T. (Org.) Educação, inclusão e exclusão social: contribuiçôes para o debate. Curitiba: Aos Quatro ventos, 2007. p. 136-144.

ELKIND, D. Crianças e adolescentes. Ensaios interpretativos sobre Jean Piaget. Rio de Janeiro: Zahar, 1975.

FERNANDES JÜNIOR, N. Representaçôes de prevenção à gravidezprecoce e DST em adolescentes. 2005. Dissertação (Mestrado em Educação). Universidade Federal do Paraná. Curitiba, PR.

GIL, A. C. Métodos e técnicas de pesquisa social. 5.ed. São Paulo: Atlas, 1999.

GLASEL, M. Práticas sexuais de alto risco na transmissão da AIDS/SIDA. In: DE VITA JR, V.T.; HELLMAN, S.; ROSEMBERG, S.A. AIDS/SIDA: etiologia, diagnóstico, tratamento e prevenção. 2.ed. Rio de Janeiro: Revinter, 1991. p.363-376.

MOREIRA, M. de M. Adolescentes e jovens do sexo masculino: riscos de contrair HIV/AIDS ou DST ou engravidar uma parceira. In: XIII Encontro da Associação Brasileira de Estudos Populacionais. 2002. Ouro Preto, Minas Gerais: Anais, 2002.

MOTA, M. P. da. Gender and sexuality: fragments of male identity in the Aids era. Cad. Saude Pública.v.14.n.1. jan./mar.1998. p.145-155. ISSN 0102-311X.

PASCHOALICK, R. C. Saúde sexuale reprodutiva: representaçốes e práticas do adolescente masculino, sob a ótica da enfermagem. 2007. Dissertação (Mestrado em Enfermagem). Universidade Federal do Paraná. Curitiba, PR.

PIAGET, J. Seis estudos de psicologia. São Paulo: Forense. 1969.

PIAGET, J.; INHELDER, B. Da lógica da criança à lógica do adolescente. São Paulo: Pioncira, 1976, [1955].

UNAIDS. Fatos e números: Campanha Mundial da Aids - 1999. In: Listen, Leam, Live! World Aids Campaign with children and youngpeople. Genebra, 1999.

UNESCO. AIDS: o que pensam os jovens - Políticas e práticas educativas. Brasília/UNESCO, 2002.88p. Disponível em: <http://www.adolec.br/bvs/adoled/P/pdf/AIDS.pdfs. Acesso cm: 12 mai. 2004.

UNFPA. The state of World Population 2003: Making 1 Billion Count: Investing in adolescents' Health and Rights. UNFPA, ONU: London, 2003.

UNFPA State of Word Population 2003. Disponivel em: <http://unfpa.org/swp/2003/English/ ch1/index htm >. Acesso em: 24 abr. 2003. <http:/www.unfpa.org/swp/2003/pdf/spanish/ swp2003_spa.pdf>. Acesso em: 24 abr. 2003.

Recebido em maio de 2007 e aprovado em agosto de 2007. 